\title{
No Needle Mesotherapy Device in Treatment of Corticosteroid Induced Striae in Systemic Lupus Erythematosus Patients
}

\author{
Sahar S. Ganeb, Refaat M. Eltanawy, Shimaa M. Eid Soliman, Rasha M. Fawzy
}

\begin{abstract}
Department of Rheumatology, Rehabilitation and Physical Medicine Faculty of Medicine Benha University, Egypt.

Correspondence to: Rasha M. Fawzy, Department of Rheumatology, Rehabilitation and Physical Medicine Faculty of Medicine Benha University, Egypt.
\end{abstract}

Email:

rashafawzybenha@gmail.com

Received: 8 May 2020

Accepted: 25 July 2021

\begin{abstract}
:
Introduction: Mesostyle is a needle free mesotheraputic device that is able to insert analytical pure active substance to the deep layers of skin within cell levels using the most modern electroporation procedure. Objectives: this study aimed to assess electroporation "as a method of transdermal administration of medications" in treatment of corticosteroid induced striae in systemic lupus erythematosus patients (SLE). Methods: Twenty SLE female patients suffering from corticosteroid induced striae in different body parts, were included in this study. Each patient received six successive weekly sessions using electroporation device "Mesostyle" and photos were obtained after each cession. Results: We found marked improvement of striae appearance with noticeable patients' satisfaction without any adverse effects. Conclusion: This study supports the role of electroporation, which is safe, tolerable, non-invasive, and effective method for transdermal administration of medications.
\end{abstract}

Keywords: Electroporation, striae, systemic lupus erythematosus

\section{Introduction}

Systemic lupus erythematous (SLE), is a chronic autoimmune disorder. The exact etiology of SLE is not completely understood. It is thought to be due to environmental factors that trigger immune response in genetically susceptible individuals. Elevated body temperature, polyarthralgia, tender swollen joints, hair loss, oral ulcers, skin rash are the main presentations of SLE patients. Disease course undergoes periods of wane and flare (1). Treatment of SLE is directed by the individual patient's manifestations. Commonly used drugs are hydroxychloroquine, nonsteroidal anti-inflammatory drugs 
(NSAIDS), immuno- suppressive drugs(DMARDS and steroids. Steroids are used in low doses in mild conditions while, pulse high dose steroid used in life threatening conditions(2).

Skin thinning, telangiectasia, delayed healing of wounds, stretch marks (striae), steroid acne, and hypertrichosis complicate long-term systemic steroids (3).

Linear visible scars known as striae commonly happen owing to dermal destruction in over stretched skin. Hormones (corticosteroids), mechanical stress and genetic predisposition may have a role. Early lesions might be elevated and irritable later on they converted flat, smooth and livid red or bluish in color.(striae rubra) (4)

Mesotherapy, is one of the modalities, used to rejuvenate and tone the skin. Rejuvenation is maintenance and restoration of healthy and useful texture of the skin. It involves intradermal introduction of pharmacological substances, such as nutrients, vitamins, enzymes, hormones and natural plant extracts into the skin and so improving hydration and fibroblast activation (5). Electroporation is an electrically aided method for increasing drug/substance diffusion through the horny layer (6), It produces a pulsed modulated and non-ionized electromagnetic waves without generating heat that modifies the cell membrane potential, with creation of pores allowing the substances to be introduced through the skin (7).

Methods: This is a research article study which was done from April 2018 to December 2018.

This clinical trial included twenty systemic lupus erythematous female patients fulfilling SLICC Classification Criteria (Systemic Lupus Erythermatosus International Collaborating clinics) 2012, suffering from striae in different body parts (8). All patients were recruited from the inpatients' and the outpatients' clinics of Rheumatology, rehabilitation \& physical medicine department, Benha University hospitals

\section{All patients were subjected for the following}

- Full history taking and examination with stress on skin and face

- Laboratory investigations: Complete blood picture (CBC), Erythrocyte sedimentation rate (ESR), serum creatinine, Aspartate transaminase (AST), serum albumin, Protein in twenty-four-hours urine collection. C3, C4, Antinuclear antibodies (ANA): presence or absence by immuno-fluoresence technique and the pattern, Anti-double-stranded DNA (Anti- 
ds DNA) antibody by the Enzyme-Linked immunosorbent assay (ELISA) technique

Ethical considerations: The protocol of this study was explained to all patients and an informed written consent was obtained prior to participation in this study and consent for photos were also obtained. This study was approved by the Ethical Medical Committee of Benha University faculty of medicine.

Criteria for exclusion: Patient $<16$ years old, pregnant or lactating females, patients with any systemic disease (1ry or 2ry) such as heart disease, renal failure, diabetes or hypothyroidism, infections other autoimmune disease, or active skin lesions, skin infections and epileptic patients and patients with known allergy to the used preparations.

\section{Procedure:}

The practical part of the study was done at the mesotherapy unit in Rheumatology, Rehabilitation \& physical medicine department at Benha University hospitals. Six successive settings were done, through this technique $2.5 \mathrm{~cm}$ of mesotherapy cocktail was applied to the skin of the affected area and the device was used in a circular motion for about 30 minutes. Photos were obtained at the base of the study then before each treatment cession. Patients were advised not to be exposed to sun light, taking a shower or use topical cosmetic preparations on the skin for at least 8-12 hours after the session and instructed to record any side effects. Our mesotherapy products were water soluble, isotonic, non-allergic and sterile having Biomimetic peptides:

\begin{tabular}{|c|c|c|c|c|c|}
\hline Category & $\begin{array}{c}\text { Hexa- } \\
\text { peptides } 10\end{array}$ & Essential Vitamins & AminoAcids & Coenzyme & Minerals: \\
\hline Ingrdients & $\begin{array}{l}\text { Tetrapeptide, } \\
\text { Acetyl arginyl } \\
\text { tryptophyl } \\
\text { diphenylglyci } \\
\text { ne,Tripeptide } \\
\text {-38,Tripeptide } \\
\text { - } \\
\text { 28,Decapeptid } \\
\text { e -3-,Copper } \\
\text { Tripeptide- 1,- } \\
\text { Decapeptide- } \\
\text { 4,- } \\
\text { Oligopeptide - } \\
\text { 24 }\end{array}$ & $\begin{array}{l}\text { Retinol(Vitamin A), } \\
\text { Pyridoxine (VitaminB6), } \\
\text { ThiamineNitrate } \\
\text { (VitaminB1), Biotin } \\
\text { (VitaminB6), } \\
\text { Tocopherol (VitaminE), } \\
\text { Riboflavin (VitaminB2), } \\
\text { Amino Benzoicacid } \\
\text { (VitaminB10),Inositol } \\
\text { (VitaminI), Niacinamide } \\
\text { (VitaminB3), } \\
\text { Cyanocobalamine } \\
\text { (VitaminB12), } \\
\text { Menadione (VitaminK), } \\
\text { Pantothenic Acid } \\
\text { (VitaminB-5), FolicAcid } \\
\text { (VitaminM }\end{array}$ & $\begin{array}{l}\text { Aminobutyric Acid, } \\
\text { Aspartic Acid, } \\
\text { GlutamicAcid, Alanine, } \\
\text { Arginine,Asparagines,Gl } \\
\text { ycine,Cysteine,Glutamin } \\
\text { e,Isoleucine,Hydroxyprol } \\
\text { ine,Histidine,Methionine, } \\
\text { Leucine,Lysine,Proline, } \\
\text { Ornithine,Phenylalanine, } \\
\text { Threonine,Serine,Valine, } \\
\text { Taurine,Tryptophan,Tyro } \\
\text { sine. } \\
\text { Antioxidants: } \\
\text { Glutathione, Ascorbic } \\
\text { Acid (Vitamin C) } \\
\text { Sodium hyaluronate } \\
\text { (Hyaluronic acid } \\
\text {-DMAE (Dimethyl } \\
\text { amino ethanol), Ideb }\end{array}$ & $\begin{array}{l}\text { CoenzymeA, } \\
\text { Nicotinamide } \\
\text { Adenine } \\
\text { Dinucleotide } \\
\text { (NAD), Thiamine } \\
\text { Diphosphate, } \\
\text { Flavin } \\
\text { Adenine(FAD( } \\
\text {-- } \\
\text {-NucleicAcid: } \\
\text { Cyclic Adenosine } \\
\text { Phosphate,. }\end{array}$ & $\begin{array}{l}\text { Nucleic Acid: } \\
\text { Cyclic Adenosine } \\
\text { Phosphate, } \\
\text { Guanosine, } \\
\text { Cytosine, Thymine }\end{array}$ \\
\hline
\end{tabular}




\section{Statistical analysis}

All data were collected, tabulated and statistically analyzed using STATA/SE version 11.2 for Windows (STATA Corporation, College Station, Texas). The collected data were summarized in terms of mean \pm Standard Deviation $(\mathrm{SD})$ and range for quantitative data and number and percentage for qualitative data.

\section{Results}

This study was conducted on 20 SLE female patients. Their ages ranged 18-32 years old with mean \pm SD of $25.68 \pm 4.76$ years. Disease duration ranged 1-5 years with mean \pm SD of $4.1 \pm 1.27$. Eight patients came with striae at underarms, six in the abdomen, four in the back and two in inner thigh. The SLEDAI 2K score: ranged 4-6 with mean \pm SD of $4.4 \pm 2.76$.

No adverse reactions were reported after mesotherapy sessions in the treated patients.

\section{Striae improvement}

We measured striae improvement on a scale from 0 to 10 , where 0 is no improvement and 10 is the maximum improvement, adding patient's degree of improvement (010) and the doctor's view of improvement (0-10) using the same scale, then adding the two numbers with the maximum of 20 and dividing it on 2 to obtain the degree of improvement from :0-10

Degree of improvement $=$ patient's degree of improvement + doctor's view (divided on 2 ) of improvement

The score to detect the degree of improvement used as followed: mild improvement<4, moderate improvement :46, marked improvement: 7-10

\section{Discussion}

Systemic lupus erythematosus (SLE) is a chronic, inflammatory, disease (9). Corticosteroids are commonly used drugs in therapeutic regimens, which induce striae. Electroporation is a modality that used in management of striae, it is the creation of aqueous pores in the lipid layer of the cellular membrane, for the application of a short electrical impulse (10).

To the best of our knowledge this is the first study to be done aiming to assess electroporation in improving corticosteroid induced striae in SLE patients.

Twenty female patients suffering from corticosteroid induced striae in the 
abdominal region, under arms area, inner thigh and the back were included in this study (8). In our study, there was marked improvement of striae appearance in 13 cases and moderate improvement in the last 7 cases.

The main active ingredient in our mesotherapy cocktail was sodium hyaluronate. Natalia et al., (12) stated that hyaluronic acid is used to promote an optimal level of hydration in the skin, protect against loss of elasticity.

In our work, we used many Peptides such as Hexapeptide10, Tetrapeptid, Tripeptide38, Decapeptide-3,Tripeptide 28, Copper, tripeptide $\quad 1, \quad$ Decapeptide-4,and Oligopeptide-24.

Gazitaeva et al., (13) studied the antiaging effects produced by the use of biomimetic peptides on the restoration processes in vivo in the dermis and in vitro by the use of cell cultures (13). We used Amino acids such as amino butyric Acid, Aspartic Acid, Glutamic Acid, Alanine, Arginine, Asparagines, Glycine, Cysteine, Glutamine, Isoleucine, Hydroxyproline. Motoko et al., (14) found that there was significant improvement of the skin texture by the continuous intake of the amino-acid supplement.

We used Coenzyme such as Coenzyme A, Nicotinamide Adenine Dinucleotide (NAD), Thiamine Diphosphate, Flavin Adenine (FAD). Sergey (15) found that coenzyme acts as catalysts that speed up metabolic reactions

We used Antioxidants such as Glutathione , Ascorbic Acid (Vitamin C). High-dose of vitamin $\mathrm{C}$ supplementation significantly enhanced the effect of treatment with shortterm UVB irradiation in patients diagnosed with vitiligo, particularly in the UVBirradiated areas of skin (16).

\section{Conclusion}

This study supports the role of electroporation which is safe, tolerable, noninvasive, and effective method for transdermal administration of drugs. Further studies are needed on larger numbers of patients using not only subjective methods but also objective methods to further prove our results.

\section{References}

1. Ntatsaki E, Isenberg D. Risk factors for renal disease in systemic lupus erythematosus and their clinical implications. Expert Rev Clin Immunol. 2015;11(7):837-48 .

2. Van Vollenhoven RF, Mosca M, Bertsias G, Isenberg D, Kuhn A, Lerstrøm K, et al. Treat- 
to-target in systemic lupus erythematosus: recommendations from an international task force. Ann Rheum Dis. 2014;73(6):958-67.

3. Ting P, Barankin B. Atrophic patches. Can Fam Physician. 2006;52(12):1547 .

4. Cho S, Park ES, Lee DH, Li K, Chung JH. Clinical features and risk factors for striae distensae in Korean adolescents. J Eur Acad Dermatology Venereol. 2006;20(9):1108-13 .

5. Andre P. New trends in face rejuvenation by hyaluronic acid injections. J Cosmet Dermatol. 2008;7(4):251-8 .

6. Kotnik T, Rems L, Tarek M, Miklavčič D. Membrane electroporation and electropermeabilization: mechanisms and models. Annu Rev Biophys. 2019;48:63-91 .

7. Kappes UP. Skin ageing and wrinkles: clinical and photographic scoring. J Cosmet Dermatol. 2004;3(1):23-5.

8. Petri M, Orbai A, Alarcón GS, Gordon C, Merrill JT, Fortin PR, et al. Derivation and validation of the Systemic Lupus International Collaborating Clinics classification criteria for systemic lupus erythematosus. Arthritis Rheum. 2012;64(8):2677-86 .

9. Hiraki LT, Feldman CH, Liu J, Alarcón GS, Fischer MA, Winkelmayer WC, et al. Prevalence, incidence, and demographics of systemic lupus erythematosus and lupus nephritis from 2000 to 2004 among children in the US Medicaid beneficiary population. Arthritis Rheum. 2012;64(8):2669-76 .

10. Shah B, Surti N, Misra A. Other Routes of Protein and Peptide Delivery: Transdermal,
Topical, Uterine, and Rectal0. In: Challenges in Delivery of Therapeutic Genomics and Proteomics. Elsevier; 2011. p. 623-71 .

11. Blumrosen G, Abazari A, Golberg A, Yarmush ML, Toner M. Single-step electrical field strength screening to determine electroporation induced transmembrane transport parameters. Biochim Biophys Acta (BBA) Biomembranes. 2016;1858 (9):2041-9 .

12. Salwowska NM, Bebenek KA, Żądło DA, Wcisło-Dziadecka DL. Physiochemical properties and application of hyaluronic acid: a systematic review. J Cosmet Dermatol. 2016;15(4):520-6 .

13. Gazitaeva ZI, Drobintseva AO, Chung Y, Polyakova VO, Kvetnoy IM. Cosmeceutical product consisting of biomimetic peptides: antiaging effects in vivo and in vitro. Clin Cosmet Investig Dermatol. 2017;10:11 .

14. Takaoka M, Okumura S, Seki T, Ohtani M. Effect of amino-acid intake on physical conditions and skin state: a randomized, doubleblind, placeba randomized, double-blind, placebo-controlled, crossover trial. J Clin Biochem Nutr. 2019;65(1):52-8 .

15. Prikhnenko S. Polycomponent mesotherapy formulations for the treatment of skin aging and improvement of skin quality. Clin Cosmet Investig Dermatol. 2015;8:151 .

16. Don $\mathbf{P}$, Iuga A, Dacko A, Hardick $K$. Treatment of vitiligo with broadband ultraviolet B and vitamins. Int J Dermatol. 2006;45(1):635.

To cite this article: Sahar S. Ganeb, Refaat M. Eltanawy, Shimaa M. Eid Soliman, Rasha M. Fawzy. No Needle Mesotherapy Device in Treatment of Corticosteroid Induced Striae in Systemic Lupus Erythematosus Patients. BMFJ 2021;38(3): 825-830. DOI: 10.21608/bmfj.2021.29732.1259 